\title{
Genome composition and assessment of the divergence between Russian boreal species in the genus Elymus (Poaceae) detected on the basis of sequencing of the nuclear gene GBSSI
}

\author{
Elena Kobozeva*, Sergey Asbaganov, and Alexander Agafonov \\ Central Siberian Botanical Garden SB RAS, Zolotodolinskaya st., 101, Novosibirsk, Russia, 630090
}

\begin{abstract}
A comparative study of the sequence of GBSSI gene fragments in 10 species of the genus Elymus growing in the territory of Asian Russia was carried out. Data on the genomic composition and on the levels of interspecific divergence were obtained. This information is a necessary requirement for the construction of phylogenetically oriented taxonomic system of the genus Elymus within Russia.
\end{abstract}

\section{Introduction}

Serial studies conducted previously confirming that the cytogenetic data for the genomic constitution and evolutionary relationships both among North American [1] and Asian species of the genus Elymus [2] significantly complement the molecular phylogenetic analysis of the single-copy GBSSI gene. This paper presents the results of a comparative study of the sequence of the GBSSI gene in 10 Elymus species growing on the territory of Siberia and the Russian Far East in order to determine their genomic constitution and to assess the levels of divergence and phylogenetic differentiation. This information is a necessary requirement for the construction of a phylogenetically-oriented taxonomic system of the genus within Russia.

\section{Materials and Methods}

The plant material of species, which was thoroughly taxonomically identified, was used in the work. The set of samples included species of the genus Elymus common in the Asian part of Russia with an unidentified genomic constitution.

All procedures for DNA extraction, cloning and sample preparation for sequencing were performed according to the generally accepted protocols proposed earlier by R. Mason-Gamer [3].

The plasmids were checked for the presence of insertions by electrophoresis in a $1 \%$ agarose gel. The products of the Sanger reaction were purified and analyzed on the automatic gene analyzer ABI PRIZM 3130XL on the basis of the Central Committee of the

* Corresponding author: ekobozeva87@mail.ru 
SB RAS "Genomics". Chromatograms were subsequently tested and corrected in Unipro UGENE v1.20.0 [4]. From each species sample, 6 clones of the GBSSI gene fragment from 9 to 14 exons were obtained and sequenced [3]. Genetic distances were calculated using the model of the nucleotide substitutions [5]. The construction of dendrograms by the method of Neighbor-Joining was carried out in the program TREECON ver. 1.3b [6]. Gene sequences in species bearing the marker genomes St, $\mathrm{H}$ and $\mathrm{Y}$ were drawn from the NCBI database.

Accessions and clones of the following species were studied: E. kamczadalorum (Nevski) Tzvel. H10432, clones Kamcz_781-786; E. charkeviczii Probat. H10470, clones Chark_791-796; E. kronokensis (Kom.) Tzvel. KES-9603, clones Kron_801-806; E. lenensis (M. Pop.) Tzvel. 12-0125, clones Lenen_811-816; E. subfibrosus (Tzvel.) Tzvel., ANA-1181, clones Subfib_821-826; E. macrourus (Turcz.) Tzvel. 12-0135, clones Macro_831-836; E. jacutensis (Drob.) Tzvel. 13-0443, clones Jacut_841-846; E. komarovii (Nevski) Tzvel. GAR-0501, clones Komar_851-856; E. transbaicalensis (Nevski) Tzvel. GAR-0530, clones Trans_861-866; E. sajanensis (Nevski) Tzvel. ZUN-0502, clones Sajan_871-876.

\section{Results and Discussions}

The dendrogram constructed by the NJ method (Figure 1) clarified not only the macro-, but also microevolutionary events, confirming our previous results of complex biosystematic studies on the analyzed group of boreal species of Siberia and the Far East of Russia. In all studied species, gene variants were found, unique to St and $\mathrm{H}$ genomes. This means that these species belong to the tetraploid StH-genome group. If we examine the location of the samples inside clades of subgenomes, then the clusters combined the species accessions according to the assumed relation. Thus, the species E. jacutensis and E. macrourus were united in common clusters in both major $\mathrm{H}$ - and St-clades, thereby confirming the previously assumptions that E. jacutensis is an awned form of E. macrourus $[7,8]$. This fact agrees with the data on comparative morphological and electrophoretic analysis and hybridization of selective biotypes of these species [9].

Clones of E. kamczadalorum were united in a separate cluster, in which the most closely related were the North American species E. trachycaulus $3 \mathrm{a}$ and $3 \mathrm{~b}$, which confirms the hypothesis of a phylogenetic connection between species from Kamchatka and North America. At the same time, the isolation of E. kamczadalorum from the Kamchatka species E. charkeviczii was confirmed, that was discovered earlier with the help of comparative morphology, endosperm proteins electrophoresis, sexual hybridization [10] and molecular ISSR analysis [11]. Inside the clades of subgenome $\mathrm{H}$, clones E. charkeviczii and the reference clone E. mutabilis 2b_H from the Altai Mountains showed a reliable link. This still requires an explanation, taken into account the geographical remoteness of the collection points for biotypes. In the clade of St subgenome, E. kronokensis, E. sajanensis and E. lenensis were united in a common cluster, which also does not contradict our previously obtained data on the phylogenetic proximity of the first two species. Previously, for the new combination E. lenensis (M. Pop.) Tzvel. N.N. Tzvelev noted the close relation of this species to E. kronokensis. [8]. 


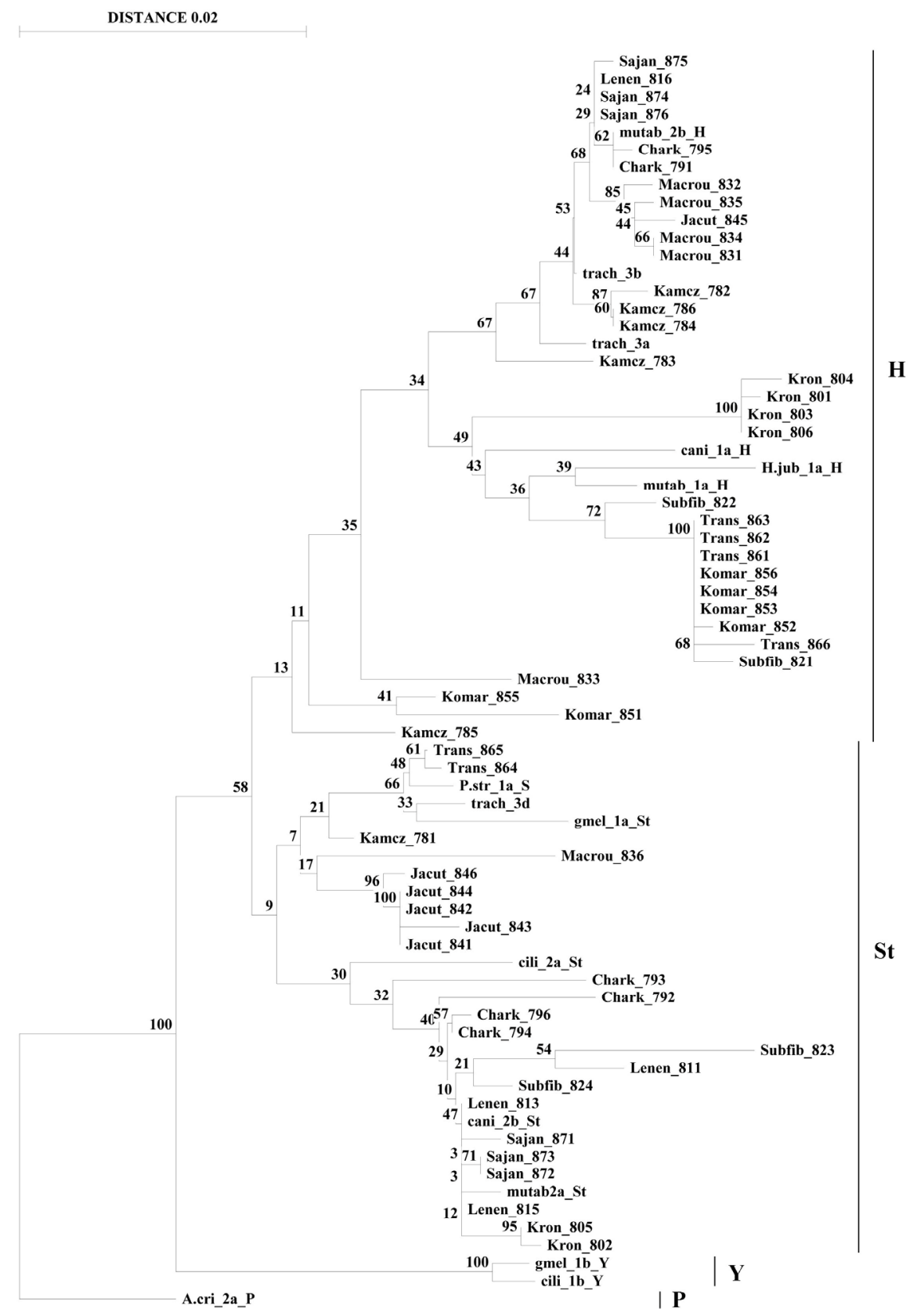

Fig. 1. NJ dendrogram based on the results of sequences of the gene GBSSI exons in 10 species of the genus Elymus from the Asian part of Russia. Clones drawn from the NCBI: E. trachycaulus (trach_3a_H, trach_3b_H, trach_1b_S); E. caninus (cani_2b_St, cani_1a_H); E. mutabilis (mutab_2a_H, mutab_2b_H); E. ciliaris (cili_2a_St, cili_1b_Y); E. gmelinii (gmel_1a_St, gmel_1b_Y); Hordeum jubatum (H.jub_1a_H); Pseudoroegneria strigosa (P.str_1a_S); Agropyrum cristatum (A.cri_2a_P).

Species E. komarovii and E. transbaicalensis, as expected, formed a common cluster. One of the reasons was the joint growth of these biotypes in relatively close populations. 
Since in mixed populations of these species there is active hybridization and introgression, the results of the analysis require confirmation with the use of accessions from different locations of growth of these species, both jointly and separately. According to our longterm observations, the species E. komarovii and E. transbaicalensis are genetically independent, but not always morphologically distinct. Modern processes of hybridization and introgression can lead not only to new interspecific biotypes and micropopulations, but also to the formation of new species.

One of the most difficult species for identification is E. subfibrosus. The accession collected in the regional population of Anadyr (Chukotka) is grouped in a clade of $\mathrm{H}$ genomic clones together with morphologically close E. komarovii and E. transbaicalensis from Siberia. Obviously, for study of such polymorphic species with a wide area in Siberia and the Russian Far East more biotypes from different populations are needed.

To construct a new phylogenetically oriented genus system, as the first step, it is necessary to classify intra-genus taxa based on the genomic constitution of the species. The generic system should be based on the taxonomic model of microevolutionary groups, which are evolving through hybridization and introgression. The degree of relationships between taxa can be determined using biosystematics methods with the determination of the crossability of individuals. Taking into account previous biosystematic studies, we proposed the principle of constructing a model of microevolutionary groups of some boreal allotetraploid Elymus taxa in the territory of Russia. Each microevolutionary group should be considered as a branched system of species and intraspecies taxa. Therefore, the system of the genus will be presented as phylogenetically confirmed structure.

Taxonomic ranks of different microevolutionary groups could be defined as subspecies, sections, subsections or aggregate species in a broad sense. Probably, it might be appropriate to recognize subgenera within the genus Elymus, since the species growing on the territory of Russia according to recent treatments [12] were combined into sections without consideration of their genomic constitution.

\section{References}

1. R.J. Mason-Gamer, Syst. Bot. 26, 757-768 (2001)

2. R.J. Mason-Gamer, M. M. Burns, M. Naum, Mol. Phylogenet. Evol. 54, 10-22 (2010)

3. R. J. Mason-Gamer, C.F. Weil, E.A. Kellogg, Mol. Biol. Evol. 15, 1658-1673 (1998)

4. K. Okonechnikov, O. Golosova, M. Fursov, Bioinformatics 28, 1166-1167 (2012)

5. M. Kimura, J. Mol. Evol. 16, 111-120 (1980)

6. Y. Van de Peer, R. De Wachter, Computer Applications in Biosciences 10, 569-570 (1994)

7. N.N. Tzvelev, Arkticheskaya flora SSSR 2, 230-247 (1964) (in Russian)

8. N.N. Tzvelev, Novosti sistematiki vysshikh rastenij 10, 19-59 (1973) (in Russian)

9. A.V. Agafonov, Plant Life of Asian Russia 2, 20-32 (2008) (in Russian)

10. A.V. Agafonov, D.E. Gerus, B. Salomon, Czech J. Genet. Plant Breed 41, 79-85 (2005)

11. E.V. Kobozeva, M.V. Emtseva, S.V. Asbaganov, A.V. Agafonov, Plant Life of Asian Russia 3, 43-50 (2017) (in Russian)

12. N.N. Tzvelev, N.S. Probatova, Komarovskiye chteniya 57, 5-102 (2010) (in Russian) 